\title{
Medical complications during inpatient rehabilitation in patients with ischemic stroke in a tertiary care hospital in Nepal
}

\author{
Dhungana $\mathrm{K}^{1}$, Shakya $\mathrm{D}^{2}$, Shrestha $\mathrm{R}^{3}$, Bhatta $\mathrm{S}^{4}$, Maharjan $\mathrm{S}^{4}$ \\ ${ }^{1}$ Krishna Dhungana, Associate Professor; ${ }^{2}$ Dipesh Shakya, Assistant Professor; ${ }^{3}$ Rabindra Shrestha, Professor and HOD; \\ ${ }^{4}$ Sabnam Bhatta; ${ }^{4}$ Sabbu Maharjan, Medical Officer, Department of Neurology, Kathmandu Medical College Teaching \\ Hospital, Kathmandu, Nepal.
}

\begin{abstract}
Background: Complications are common in patients with ischemic stroke and hinder successful rehabilitation. Timely identification and management of complications are key factors in the management of patients with ischemic stroke. Objectives: The aim of this study is to find the occurrence of different types of complications in patients admitted with the diagnosis of ischemic stroke and to find the risk factors associated with the occurrence of complications.

Methodology: The study is a cross sectional descriptive study. A total of 96 patients with ischemic stroke admitted to the Department of Neurology of Kathmandu Medical College Teaching Hospital over a period of six months (July 2018 to December 2018) were recruited. Data was recorded according to a designed proforma and analysed using Statistical Package for the Social Sciences version 20.

Results: The age group ranged from 25 to 91 years with the mean age of 64.36 years and 50 (52.1\%)patients were male. A total of $62(64.6 \%)$ patients developed at least one complication during hospital stay. Pneumonia and urinary tract infection were the most common complications occurring in 22(22.9\%) patients. The occurrence of complications was positively correlated with National Institutes of Health Stroke Scale and Glasgow Coma Scale.

Conclusion: Pneumonia and urinary tract infection were the most common complications in our study and were similar to those quoted in the western literature. Severity of stroke had positive correlations with occurrence of complications.
\end{abstract}

Key words: Complications; GCS; NIHSS; Pneumonia.

DOI: https://doi.org/10.3126/jkmc.v8i3.29724

\section{INTRODUCTION}

troke is classically characterized as a neurological $\checkmark$ deficit attributed to an acute focal injury of the central nervous system (CNS) by a vascular cause, including cerebral infarction, intracerebral haemorrhage $(\mathrm{ICH})$, and subarachnoid haemorrhage (SAH), and is a major cause of disability and mortality worldwide?

Address for correspondence

\section{Dr. Krishna Dhungana}

Associate Professor, Department of Neurology

Kathmandu Medical College Teaching Hospital

Sinamangal, Kathmandu, Nepal

E-mail: dhungana.krish@gmail.com

ORCID: https://orcid.org/0000-0002-2693-5926

ORCID: DipeshShakya: https://orcid.org/0000-0003-2486-9811 Rabindra Shrestha: https://orcid.org/0000-0002-6622-2306 Sabnam Bhatta: https://orcid.org/0000-0003-3479-1536 Sabbu Maharjan: https://orcid.org/0000-0001-8802-0118
Complications are a major problem after acute stroke, and may manifest as neurological or non-neurological. They play a major role in prolonged duration of hospital stay and recovery of a patient. Whilst complications of stroke may modify the natural course of the disease, they might also delay successful rehabilitations and may eventually lead to death. Several studies have suggested that complications are quite common with the estimated frequency ranging from $40 \%$ to $96 \%$ of the patients ${ }^{2-7}$. Not only are the complications common, but are also related to poor patient outcomes ${ }^{6}$.

It has been suggested that the effectiveness of organized stroke care in reducing mortality ${ }^{8}$ may be due to improvements in prevention, identification, and treatment of secondary complications ${ }^{9}$. Complication rates may also be a useful measure of outcome in comparative studies, and they have been used in both 
non-randomized ${ }^{10-12}$ and randomized controlled trials ${ }^{13}$ of stroke units.

To the best of my knowledge, study regarding complications of stroke has not yet been published in context of Nepalese population. Thus, this study aims to study if the types of complications found in this demography are comparable with the studies done elsewhere.Moreover, the study aims to find the risk factors which are directly associated with the occurrence of certain complications in patients with acute stroke.

\section{METHODOLOGY}

The study was a cross sectional descriptive study. Ninety-six patients with ischemic stroke admitted to the Department of Neurology of Kathmandu Medical College Teaching Hospital (KMCTH) over a period of six months starting from July 2018 to December 2018, were recruited.The calculated sample size was 96 and convenient purposive sampling method was used. The sample size was calculated by the formula $N=Z^{2} p q /$ $\mathrm{d}^{2}$ where $\mathrm{Z}$ is the standard normal deviation (usually set as 1.96), $d=$ degree of accuracy required (we take at $10 \%$ error), $\mathrm{p}=$ proportion in the target population estimated to have a particular characteristic (since there is no reasonable estimation done in $\mathrm{KMCTH}$, we use $50 \%$ ) and $q=1-p$. Patients were randomly selected from among all admitted inthe Medicine Intensive Care Unit (MICU), Medicine High care ward and Neurology ward. All patients with clinical diagnosis of ischemic stroke more than 16 years of age were included;patients with subarachnoid haemorrhage and intracerebral haemorrhage were excluded from the study. Patients were recruited within three days of admission and were followed every three days until discharge. The initial assessment included demographic details and National Institutes of Health Stroke Scale (NIHSS). For hospital follow up, simple clinical definitions of complications were used that were modified from those of Davenport et $\mathrm{al}^{2}$. Written informed consent was taken from the patient or their surrogate for the study and ethical clearance was obtained from the Institutional Review Committee of KMCTH.

Data was recorded according to the pre-designed proforma and entered into Statistical Package for the Social Sciences (SPSS) version 20 for analysis. Demographic and baseline characteristics were evaluated using descriptive statistics. Statistical significance was considered with $p$ value less than 0.05 . Categorical data were assessed using the Chi-Square test. Continuous variables were assessed using the t-test.

The proforma included demographic data including name, age, sex and address. It also included vital signs including heart rate, respiratory rate, temperature and blood pressure. National Institute of Health Stroke scale and modified Rankin scale was also included in the proforma. The proforma also included the risk factors including smoking status, history of hypertension, history of diabetes mellitus and history of cardiac arrhythmia. Finally, the proforma included investigation parameters and complications recorded in patients with ischemic stroke.

\section{RESULTS}

The age group ranged from 25 to 91 years with mean age of 64.36 with SD of 13.959 years. Fifty (52.1\%) of the patients were male. The mean duration of hospital stay was 7.36 days and ranged from one to 26 days.

Fifty-two (54.2\%) patients had NIHSS in the range of 5 to 14 representing moderate stroke and seven (7.3\%) of the patients had severe stroke (Table 2 ).

The Modified Rankin Scale was calculated at discharge and the patients with different MRS score are shown in table 3 .

Stroke was divided according to different vascular territory involved. Most of the stroke involved the middle cerebral artery (MCA) cortical territory followed by subcortical group. Distribution of stroke in different vascular territories is shown in the table 4.

A total of $62(64.6 \%)$ patients developed atleast one complication during hospital stay. Pneumonia was seen in $22.9 \%$ of patients. Deep venous thrombosis was seen in two patients (Table 5).

The relationship between NIHSS, age and sex with the occurrence of complications is shown in table 6. 
Table 1: Definitions of complications during hospital stay and follow up

\begin{tabular}{|c|c|}
\hline Complications & Definition \\
\hline Recurrent stroke & $\begin{array}{l}\text { Clinical features lasting more than } \\
24 \text { hours consistent with the World } \\
\text { Health Organization definition of } \\
\text { stroke. }\end{array}$ \\
\hline Epileptic seizure & $\begin{array}{l}\text { Clinical diagnosis of focal and/or } \\
\text { generalized seizure in a previously } \\
\text { non-epileptic patient. }\end{array}$ \\
\hline $\begin{array}{l}\text { Urinary tract } \\
\text { infection (UTI) }\end{array}$ & $\begin{array}{l}\text { Clinical symptoms of urinary tract } \\
\text { infection or positive urine culture. }\end{array}$ \\
\hline Chest infection & $\begin{array}{l}\text { Auscultatory respiratory crackles and } \\
\text { fever or radiographic evidence, or new } \\
\text { purulent sputum. }\end{array}$ \\
\hline Pressure sore & $\begin{array}{l}\text { Any skin break or necrosis resulting } \\
\text { from either pressure or trivial trauma } \\
\text { (skin trauma directly resulting from } \\
\text { fall was not included). }\end{array}$ \\
\hline $\begin{array}{l}\text { Deep venous } \\
\text { thrombosis (DVT) }\end{array}$ & $\begin{array}{l}\text { Clinical diagnosis of deep venous } \\
\text { thrombosis. }\end{array}$ \\
\hline Falls & $\begin{array}{l}\text { Any documented falls regardless of } \\
\text { cause. }\end{array}$ \\
\hline
\end{tabular}

Table 2: NIHSS score and severity

\begin{tabular}{|lc|}
\hline NIHSS score & $\begin{array}{c}\text { Number of } \\
\text { patients (n) }\end{array}$ \\
\hline 1-4 (Minor stroke) & 20 \\
\hline 5-14 (Moderate stroke) & 52 \\
15-20 (Moderate to severe stroke) & 17 \\
\hline 20 (Severe stroke) & 7 \\
\hline
\end{tabular}

Table 3: Modified Rankin Scale score of patients

\begin{tabular}{cc}
\hline MRS score & Number of patients(n) \\
\hline 1 & 10 \\
2 & 36 \\
3 & 35 \\
4 & 11 \\
5 & 4 \\
\hline
\end{tabular}

Table 4: Stroke subtypes

\begin{tabular}{lc}
\hline Stroke subtypes & $\begin{array}{c}\text { Number of } \\
\text { patients (n) }\end{array}$ \\
\hline Middle cerebral artery cortical infarct & 47 \\
\hline Subcortical infarct & 35 \\
\hline Cerebellar infarct & 6 \\
\hline Brain stem infarct & 3 \\
Middle cerebral artery+Posterior & 2 \\
cerebral artery infarct & 2 \\
\hline Anterior cerebral artery infarct & 1 \\
\hline Normal & \\
\hline
\end{tabular}

Table 5: Frequency of complications in ischemic stroke

\begin{tabular}{lc}
\hline Complications & n (\%) \\
\hline Pneumonia & $22(22.9)$ \\
\hline Epileptic seizure & $2(2.08)$ \\
\hline UTI & $22(22.9)$ \\
\hline Pressure sore & $7(9.37)$ \\
\hline DVT & $2(2.08)$ \\
\hline Falls & $3(3.12)$ \\
\hline
\end{tabular}

Table 6: Relation between NIHSS, age and sex with the occurrence of complications

\begin{tabular}{|c|c|c|c|}
\hline \multirow{2}{*}{ NIHSS } & \multicolumn{2}{|c|}{ Complications } & \multirow{2}{*}{ p-value } \\
\hline & Yes & No & \\
\hline Mild stroke & 8 & 12 & \multirow{4}{*}{0.029} \\
\hline Moderate stroke & 34 & 18 & \\
\hline Moderate to severe & 14 & 3 & \\
\hline \multirow[t]{2}{*}{ Severe } & 6 & 1 & \\
\hline & \multicolumn{2}{|c|}{ Complications } & \multirow{2}{*}{ p-value } \\
\hline Age & Yes & No & \\
\hline$<45$ years & 7 & 2 & \\
\hline 45-65 years & 26 & 15 & 0.685 \\
\hline \multirow[t]{2}{*}{$>65$ years } & 29 & 17 & \\
\hline & \multicolumn{2}{|c|}{ Complications } & n-palun \\
\hline Sex & Yes & No & $p$-value \\
\hline Male & 29 & 21 & \multirow{2}{*}{0.160} \\
\hline Female & 33 & 13 & \\
\hline
\end{tabular}

Table 7: Relation between smoking, alcohol consumption, hypertension, diabetes and Glasgow Coma Scale(GCS) with the occurrence of complications

\begin{tabular}{|c|c|c|c|}
\hline \multirow{2}{*}{ Smoking } & \multicolumn{2}{|c|}{ Complications } & \multirow{2}{*}{ p-value } \\
\hline & Yes & No & \\
\hline Yes & 32 & 16 & \multirow{2}{*}{0.670} \\
\hline No & 30 & 18 & \\
\hline Alcohol & \multicolumn{2}{|c|}{ Complications } & \multirow{2}{*}{ p-value } \\
\hline consumption & Yes & No & \\
\hline Yes & 17 & 4 & \multirow{2}{*}{0.076} \\
\hline \multirow[t]{2}{*}{ No } & 45 & 30 & \\
\hline & \multicolumn{2}{|c|}{ Complications } & \multirow{2}{*}{ p-value } \\
\hline Hypertension & Yes & No & \\
\hline Yes & 34 & 15 & \multirow{2}{*}{0.315} \\
\hline \multirow[t]{2}{*}{ No } & 28 & 19 & \\
\hline & \multicolumn{2}{|c|}{ Complications } & \multirow{2}{*}{ p-value } \\
\hline Diabetes & Yes & No & \\
\hline Yes & 12 & 5 & \multirow{2}{*}{0.568} \\
\hline \multirow[t]{3}{*}{ No } & 50 & 29 & \\
\hline & \multicolumn{2}{|c|}{ Complications } & \\
\hline & Yes & No & p-value \\
\hline Mean GCS & $13.6 \pm 2.329$ & $14.68 \pm 0.912$ & 0.002 \\
\hline
\end{tabular}




\section{DISCUSSION}

Patients who develop stroke are left with neurologic sequelae. In addition, many patients also develop other hazardous medical conditions, which hinder smooth recovery andat instances lead to mortality.

The most common risk factors in patients with stroke are diabetes, hypertension and smoking. Most of the patients fell in the NIHSS moderate stroke category. Moreover, most of the stroke incidents were found to be in the MCA cortical territory.Complications like deep venous thrombosis, epileptic seizures and falls were quite rare in patients with ischemic stroke; complications like pneumonia and urinary tract infectionswere also found.

Our study showed that pneumonia and urinary tract infection were the most common complications. Both these complications were present in 22(22.9\%) patients. Pneumonia is common because many of the patients with ischemic stroke have difficulty in swallowing and some of the patients have low Glasgow Coma Scale with risk of aspiration. The higher incidence of urinary tract infection occurred because most of the patients were on Foley's catheter as they were non-ambulant. The low frequency of pressure sore (9.37\%) and deep vein thrombosis $(2.08 \%)$ in our study may be because of intensive nursing and physiotherapy care received by the patients in our hospital. In the database derived from the placebo limb of the Randomized Trial of TirilazadMesylate in Acute Stroke (RANTTAS), the most common serious medical complication was pneumonia ${ }^{7}$. In another cohort study of a total of 1029 patients, urinary

\section{REFERENCES}

1. Sacco RL, Kasner SE, Broderick JP, Caplan LR, Connors JJ, Culebras A, et al. An Updated Definition of Stroke for the 21st Century: A Statement for Healthcare Professionals From the American Heart Association / American Stroke Association. Stroke. 2013; 44:206489.[DOI]

2. Davenport RJ, Dennis MS, Wellwood I, Warlow C. Complications after acute stroke. Stroke. 1996; 27:415-20.[DOI]

3. McClatchie G. Survey of the rehabilitation outcomes of stroke. Med J Aust. 1980; 1:649-51.[PubMed]

4. Dobkin BH. Neuromedical complications in stroke patients transferred for rehabilitation before and after diagnostic related groups. J Neurol Rehabil. 1987;1:3-7.[DOI] tract infection (31\%) was the most common medical problem ${ }^{14}$. Similarly, a study of 489 patients showed that during the first week, the most common complications were urinary tract infection in $78(16.0 \%)$ and chest infections in 55 (11.2\%), whereas, stroke recurrence, seizure, deep venous thrombosis, pulmonary embolism, and pressure sores were each present in $\leq 2.5 \%$ of the patients ${ }^{15}$.Another study of 11,757 patients showed that the most common medical complications were urinary tract infection (15.5\%) andpneumonia $(8.8 \%)^{16}$.

Stroke severity is the most important risk factor for complications in stroke.Different scales including the $\mathrm{NIH}$ stroke scale assess the severity of stroke.The severity of stroke as measured by NIHSS has positive correlations with the occurrence of complications in our study. This is because patients with higher NIHS score have low Glasgow Coma Scale and greater weakness. These patients have a higher risk of aspiration and many of them are on Foley's catheter, which make them more susceptible to develop pneumonia and urinary tract infections.

Other studies have also shown that greater severity of stroke was associated with the occurrence of complications ${ }^{15,16}$.

\section{CONCLUSION}

Common complications of stroke in our study were pneumonia and urinary tract infections and were similar to the studies done elsewhere. Similarly, low GCS and high NIHSS were associated with the occurrence of complications as seen in other studies.

5. Dromerick A, Reding M. Medical and neurological complications during inpatient stroke rehabilitation. Stroke. 1994; 25:358-61.[DOI]

6. Kalra L, Yu G, Wilson K, Roots P. Medical complications during stroke rehabilitation. Stroke. 1995; 26:990-4. [DOI]

7. Johnston KC, Li JY, Lyden PD, Hanson SK, Feasby TE, Adams R, Faught E, Haley EC, for the RANTTAS Investigators. Medical and neurological complications of ischemic stroke: experience from the RANTTAS trial. Stroke. 1999; 29:447-53.[DOI]

8. Stroke Unit Trialists' Collaboration. A systematic review of specialist multidisciplinary team (stroke unit) care for stroke inpatients. In: Warlow C, Van Gijn J, Sandercock P, eds. Stroke Module of The Cochrane Database of Systematic Reviews. London, England: BMJ Publishing Group; 1995. 
9. Donnan GA. Lifesaving for stroke. Lancet.1993; 342:383-4.[DOI]

10. Norris JW, Hachinski VC. Intensive care management of stroke patients. Stroke.1976; 7:573-7.[DOI]

11. Drake WEJ, Hamilton MJ, Carlsson M, Blumenkrantz J. Acute stroke management and patient outcome: the value of neurovascular care units (NCU). Stroke.1973; 4:933-45.[DOI]

12. Kennedy FB, Pozen TJ, Gabelman EH, Tuthill JE, Zaentz SD. Stroke intensive care: an appraisal. Am Heart J.1970; 80:188-96.[DOI]

13. Stevens RS, Ambler NR, Warren MD. A randomized controlled trial of a stroke rehabilitation ward. Age Ageing.1984; 13:65-75.[DOI]
14. Roth EJ, Lovell L, Harvey RL, Heinemann a. W, Semik P, Diaz S. Incidence of and Risk Factors for Medical Complications During Stroke Rehabilitation. Stroke. 2001;32(2):523-9.[DOI]

15. Indredavik B, Rohweder G, Naalsund E, Lydersen S. Medical Complications in a Comprehensive Stroke Unit and an Early Supported Discharge Service. Stroke.2008; 39:414-20.[DOI]

16. Ingeman A, Andersen G, Hundborg HH, Svendsen ML, Søren P. Processes of Care and Medical Complications in Patients. Stroke.2011; 42:167-72. [DOI] 